\title{
A COMPARATIVE STUDY ON THE PERFORMANCE PROPERTIES OF BREATHABLE AND NON-BREATHABLE BABY DIAPER BACK SHEET
}

\author{
Seval UYANIK, Hatice Kübra KAYNAK
}

\begin{abstract}
Disposable diapers are very important in terms of babies' health because they are in touch with the baby's skin. Disposable diapers have sheets with different functions from each other. The main layers of disposable diapers are as follows: top sheet, absorbent layer and back sheet. The function of the top sheet is to pass the liquid to the lower absorbent layer whereas the function of the absorbent layer is to absorb the liquid. As for the back sheet, this layer keeps the liquid inside and prevents it from leaving the diaper. The back sheet is usually a nonwoven/ polyethylene (PE) film composite. Considering the babies' health, breathable back sheets are mostly used in baby diapers to keep the skin drier. These have a positive effect on the baby's skin, especially in terms of occlusion, diaper dermatitis. In this study, the performance properties of some commercial baby diaper back sheet layers have been investigated. For this purpose, weight, thickness, air permeability, water vapor permeability and water resistance tests were applied to back sheet samples with different fabric mass as breathable and non-breathable films. All back sheet samples are SMS nonwoven/ polyethylene (PE) film composites. Breathable samples have a larger fabric mass than non-breathable samples. For breathable samples, while increasing mass, air permeability and water vapor permeability decrease, water resistance increases. On the other hand, the same tendency is not seen in non-breathable samples. Breathable samples have higher air permeability, water vapor permeability, water resistance, and bursting strength than non-breathable samples. Consequently, the using of a baby diaper containing breathable back sheet is more proper in terms of baby's skin health.
\end{abstract}

Keywords: air permeability; back sheet; breathable; bursting strength; non-breathable; water resistance; water vapor permeability

\section{INTRODUCTION}

The disposable diaper is one of the most significant consumer product developments of the twentieth century. Baby diapers are safely used every day by parents all over the world. Disposable diapers affect the skin's health directly because they are in close contact with the baby's skin [1]. Since single-use diapers were invented in the 1930s, they have constantly improved and become lighter over the years. Now, baby diapers are easily used, have higher comfort, better hygiene, and improvement in the number and quality [2].

The layers in a typical disposable diaper are namely: top sheet, core, breathable film, and back sheet (Fig. 1). These layers have different effects on the baby diaper thermal comfort property [3].

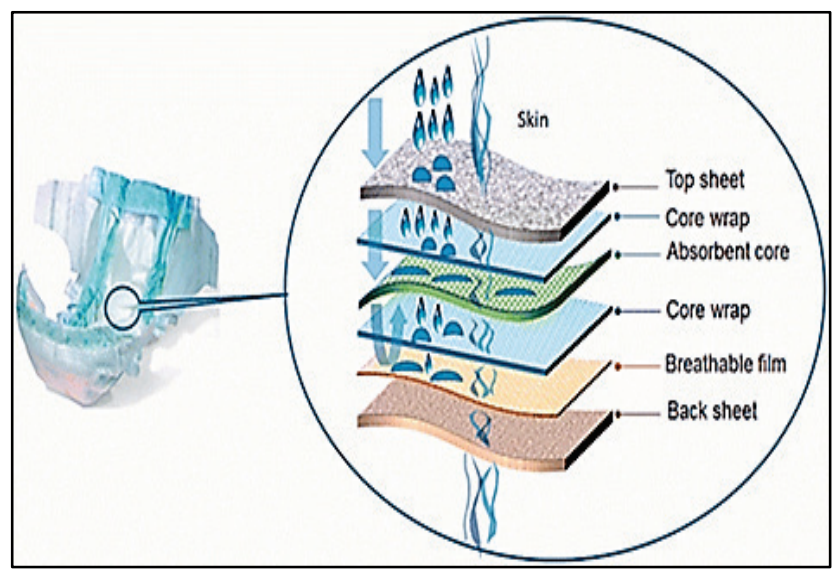

Figure 1 Diaper layers [3]

All sheets forming disposable diapers have different functions. The main layers of disposable diapers are a top sheet, absorbent layer and back sheet. The function of the top sheet is to pass the liquid to the lower absorbent layer whereas the function of the absorbent layer is to absorb the liquid. In addition, coverstock between the top sheet and the absorbent layer does not let the liquid return to the top sheet. On the other hand, the function of the back sheet is to keep the liquid inside.

In the late 1980s and early 1990s, baby diapers became thinner and a lot of innovations were made. The innovations have improved leakage control (control shields and guards, curved elastic leg openings, waste barriers); comfort (stretch sides and waist bands, cloth-like covers, breathable materials); and aesthetics (cover prints and designs, pleasing scents) [2].

Polyethylene (PE) film or a nonwoven/film composite may be used for the back sheet. This layer contributes to the product performance by preventing the liquid transfer to the outer side of the diaper. Thus this layer has a vital role by the containment of the whole structure. Also, this is the first material that the consumer comes in touch with, therefore a soft touch is an important factor. It is also required from this layer to be robust enough to fulfill its functions. On the other hand, this layer is expected to be thin and noiseless. Breathable film back sheets are widely used in the modernday absorbent products manufacture. These can help keep the skin drier, which has been shown to have a positive impact on the skin condition in the diapered area, particularly in terms of occlusion, diaper dermatitis [4].

Since the mid-90s when the "breathable" feature was first launched, many brands of baby diapers have been using permeable laminated back sheets (Fig. 2).

The easiest way to manufacture them is by adding calcium carbonate, a very fine mineral just like talc. The $\mathrm{CaCO}_{3}$ powder is added to the $\mathrm{PE}$ pellets and 
homogeneously mixed before the melting screw. Once the film is being extruded, it is stretched with a group of rollers while the film is still warm. This stretching results in millions of micro holes that are made into the film (Fig. 3) [6].
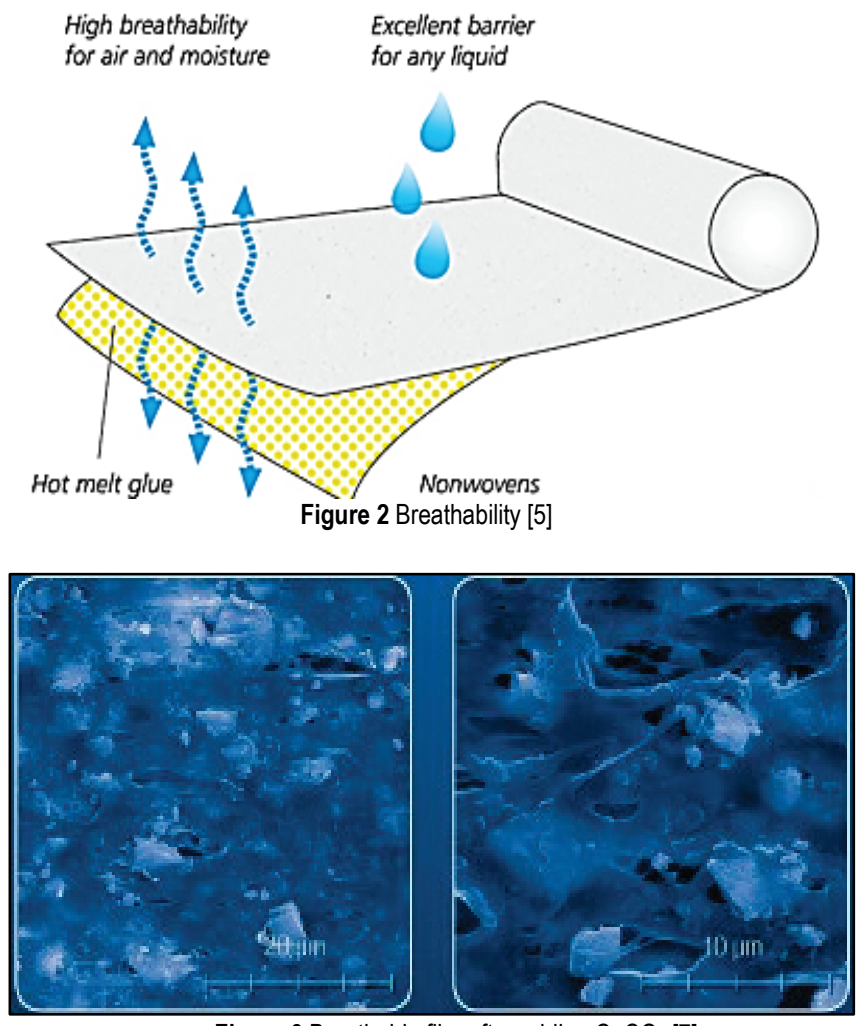

Figure 3 Breathable film after adding $\mathrm{CaCO}_{3}[7]$

The water vapor can pass through the film, but not a drop of water, so it is liquid impervious (Fig. 4) [6].

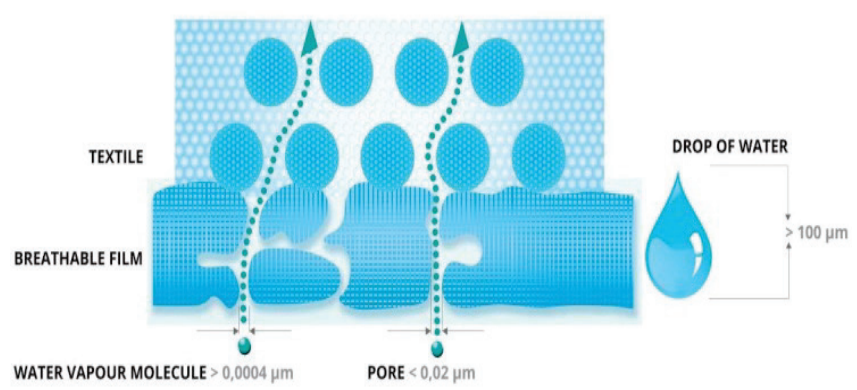

Figure 4 Breathable film [7]

This breathable film can be laminated with a nonwoven sheet using hot melt (Fig. 5) (also commonly called "hot melt lamination breathable laminate"); or extruded directly into a nonwoven sheet (also called "melt embossed breathable laminate") to create the breathable textile back sheet [6].

Typical weights for baby diaper Textile Back sheet range between $20 \mathrm{gsm}$ (as a minimum for direct melt embossed extrusion) to around $28 \mathrm{gsm}$ (as a minimum for hot melt lamination) [6].

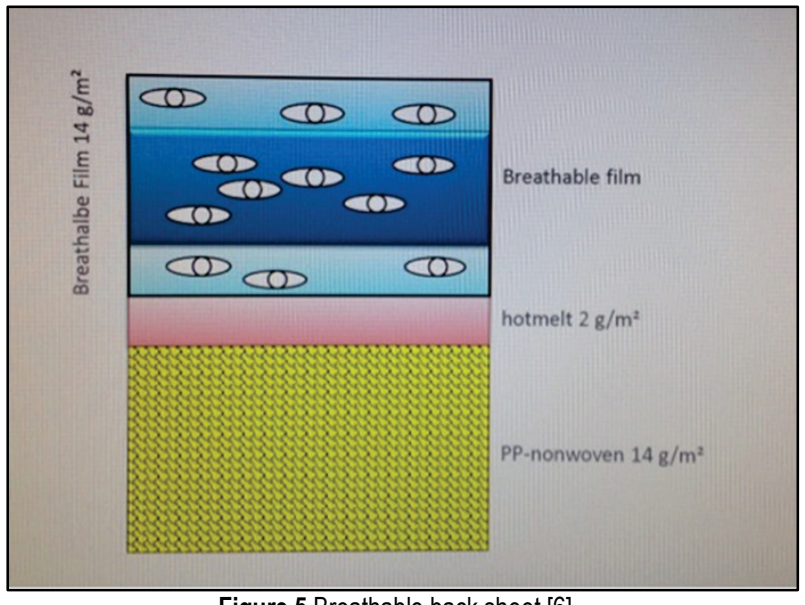

Figure 5 Breathable back sheet [6]

In the majority of previous works [8-11], thermal comfort properties i.e., thermal conductivity, heat, air, and water transport properties of one layer of diapers were investigated especially for top sheet layer.

In this study, the purpose is determining the performance properties of breathable and non-breathable baby diaper back sheet.

\section{MATERIALS AND METHODS}

All back sheet samples are SMS nonwoven/ polyethylene (PE) film composites. Fabric mass and thickness values of the samples were determined according to the standards of TS 12127 and TS 7128 EN ISO 5084 and given in Tab. 1. As seen from Tab. 1, breathable samples have a higher mass than non-breathable samples. For all samples, $1 \mathrm{~g}$ hot-melt was used for the lamination of film and nonwoven. On the other hand, there is no difference between thickness values of breathable and nonbreathable samples. Likewise, the increase in weight does not affect the thickness of the samples when breathable and non-breathable samples are examined without discrimination.

Table 1 Fabric mass and thickness values of the back sheet samples

\begin{tabular}{|l|c|c|c|}
\hline & Samples & Mass, gsm & Thickness, mm \\
\hline \multirow{3}{*}{ Non-breathable } & 1 & 23 & 0.09 \\
\cline { 2 - 4 } & 2 & 23 & 0.11 \\
\cline { 2 - 4 } & 3 & 24 & 0.11 \\
\hline \multirow{3}{*}{ Breathable } & 4 & 25 & 0.10 \\
\cline { 2 - 4 } & 5 & 26 & 0.10 \\
\cline { 2 - 4 } & 6 & 28 & 0.11 \\
\hline
\end{tabular}

In the context of this study, air permeability, water vapor permeability, water resistance and bursting strength tests were applied to back sheet samples having different fabric mass as breathable and non-breathable films in accordance with TS 391 EN ISO 9237, BS 7209, TS 257 EN 20811, and EN ISO 13938-2 standards, respectively. Moreover, independent samples T-test and Pearson correlation tests were performed via SPSS 21 package program in order to understand the statistical importance of breathability on the back sheet properties. The program was 
also used to determine the relationship between independent and dependent variables.

Air permeability test was done with digital air permeability test device at a $100 \mathrm{~Pa}$ pressure drop and a 20 $\mathrm{cm}^{2}$ test area with 5 specimens from each sample (Fig. 6).

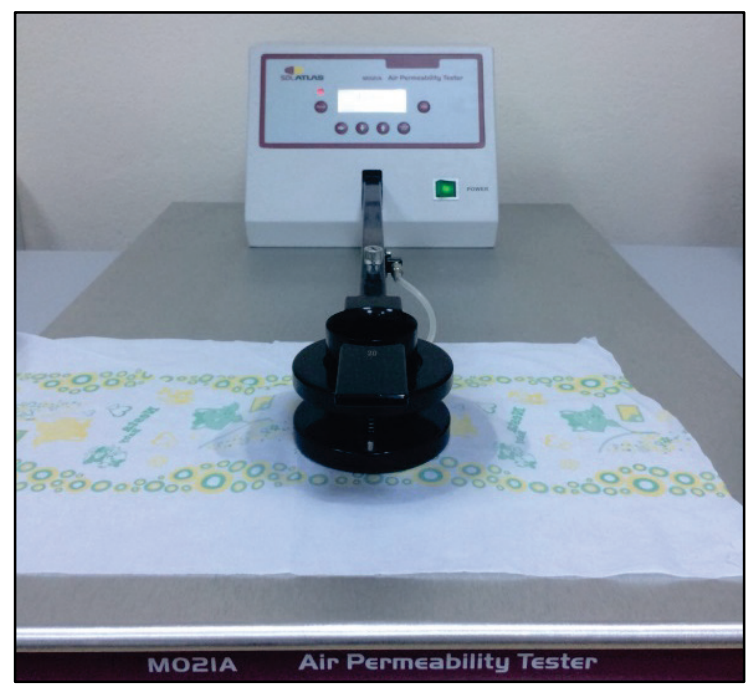

Figure 6 Air permeability test

Water vapor permeability test was done according to the evaporative dish method BS 7209:1990. Three test specimens were mounted over the test dishes containing distilled water at $20 \pm 2^{\circ} \mathrm{C}$. These dishes were placed on a rotating turntable. The samples were rotated with a turntable for one hour to establish equilibrium of water vapor pressure gradient across the sample (Fig. 7). Then, the masses of the dishes were determined. The turntable with dishes was rotated for a further 5-hour time-period. The masses of the dishes were weighed after this period. The weight difference was found.

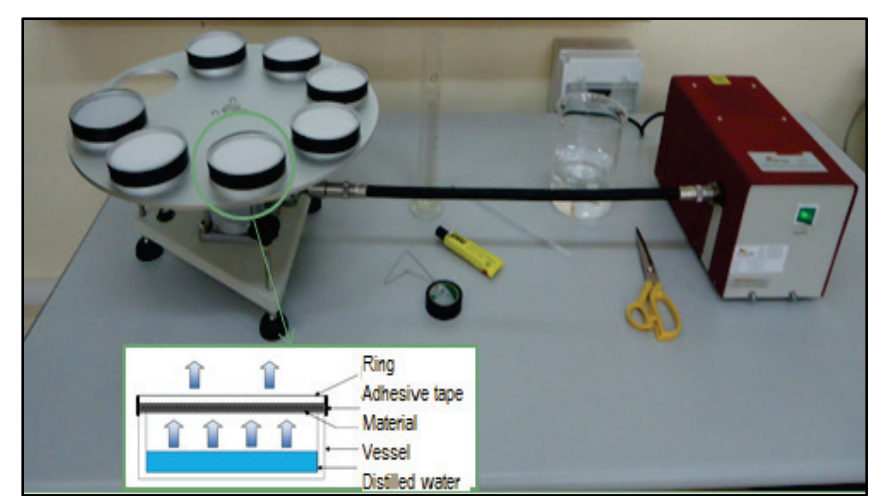

Figure 7 Water vapor permeability test (evaporative dish method)

The water vapor permeability $(W V P)$ in $\mathrm{g} / \mathrm{m}^{2} /$ day is given by the equation:

$$
W V P=\frac{24 M}{A t}
$$

where,

$M=$ loss in mass of the dish over the time period in grams $t=$ time between successive weighing of the assembly in hours

$A=$ area of the exposed sample, $5.41 \times 10^{-3} \mathrm{~m}^{2}$

Water resistance test was done with Hydrostatic head tester by Dynamic test (Fig. 8). Test head of $100 \mathrm{~cm}^{2}$ was used and the tests were performed with $10 \mathrm{~cm}$ water column $/ \mathrm{min}(\mathrm{mbar} / \mathrm{min})$ pressure increase. Five specimens were tested from each sample.

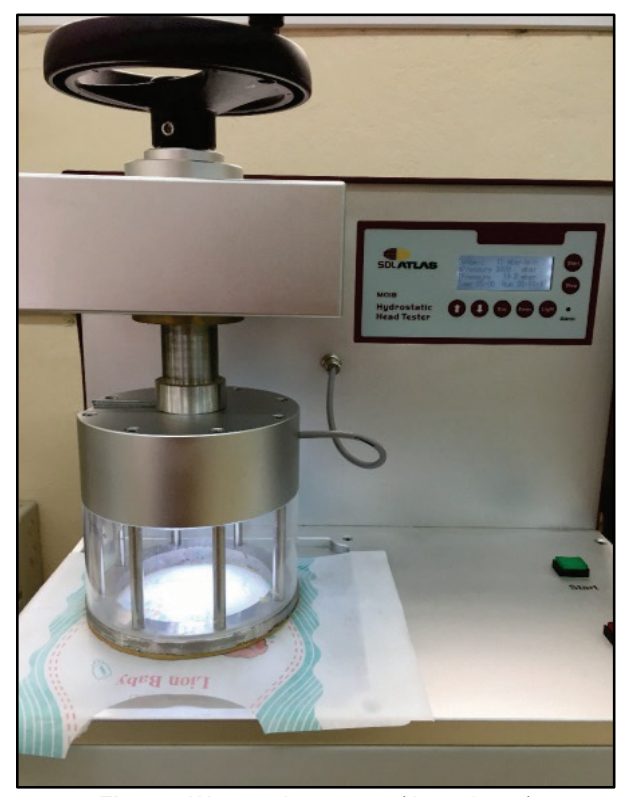

Figure 8 Water resistance test (dynamic test)

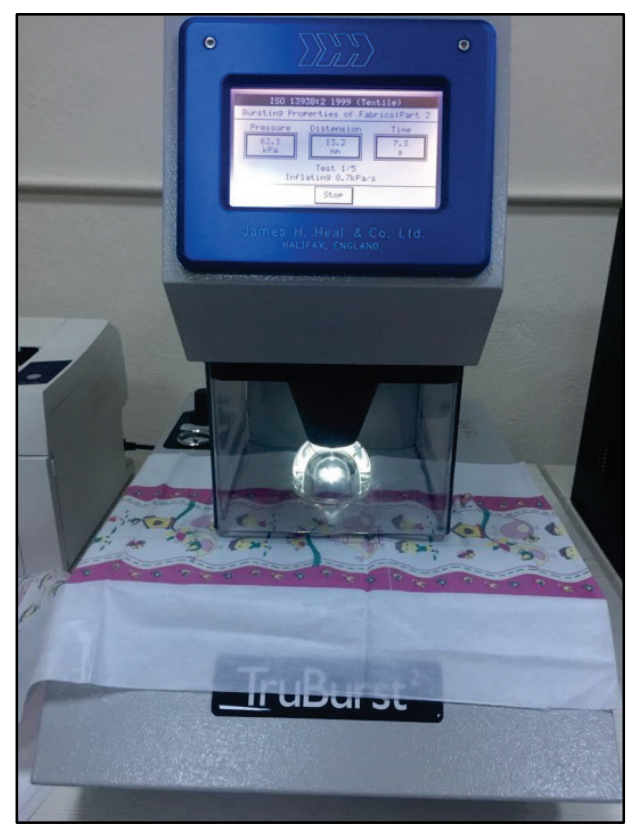

Figure 9 Bursting strength test (pneumatic method)

The bursting strength test was done by a pneumatic bursting strength test device (Fig. 9) in five different places per sample, and test results were evaluated in $\mathrm{kPa}$. The test area used in the instrument was $7.3 \mathrm{~cm}^{2}$. The tests were performed using a pneumatic method where the sample was 
placed on an elastic diaphragm and increased pneumatic pressure was applied beneath the diaphragm until the specimen burst. It should also be noted that nonwoven surfaces of the specimens were placed at the bottom.

\section{RESULTS AND DISCUSSION}

The results were analyzed under 4 headings as air permeability, water vapor permeability, water resistance, and bursting strength.

\subsection{Air permeability}

From Fig. 10, different tendencies were seen between breathable and non-breathable samples. Increase in weight increased air permeability values of the samples unexpectedly. On the contrary, increase in weight reduced these values in breathable samples.

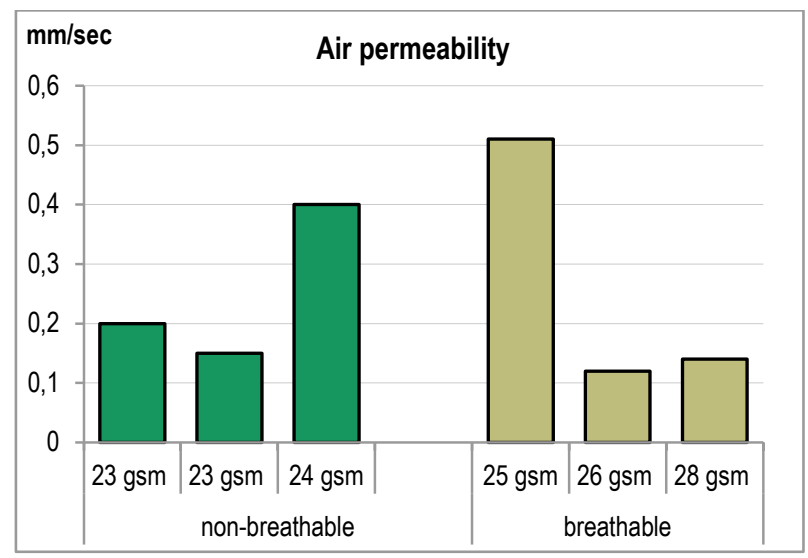

Figure 10 Air permeability

Breathability as a factor has no effect on air permeability of back sheet, since 2- tailed sig. value (0.944) $>0.05$ according to Tab. 2. Furthermore, Pearson correlation test results show that there is no relationship between breathability and air permeability.

\subsection{Water Vapor Permeability}

Breathability is a water vapor transmission with diffusion of a material and it is important for healthy skin as determined above. In terms of water vapor permeability properties of the samples, there is a very clear difference between breathable and non-breathable samples (Fig. 11). Breathable samples have noticeably higher water vapor permeability than non-breathable samples. In addition to this, water vapor permeability values decreased with increasing mass for breathable samples.

T-test results display that breathability ( $p$ value is $0.07<0.05)$ has a significant effect on water vapor permeability of back sheet. According to Pearson correlation, there is a very strong and positive relationship between breathability and water vapor permeability.

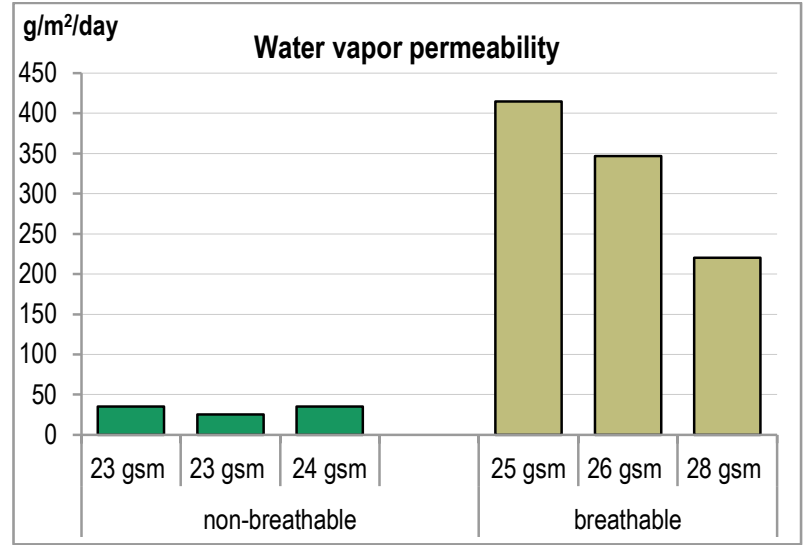

Figure 11 Water vapor permeability

\subsection{Water Resistance}

According to Fig. 12, breathable samples have higher water resistance than non-breathable samples. For breathable samples, increasing mass increased water resistance. On the other hand, the same tendency is not seen for non-breathable samples.

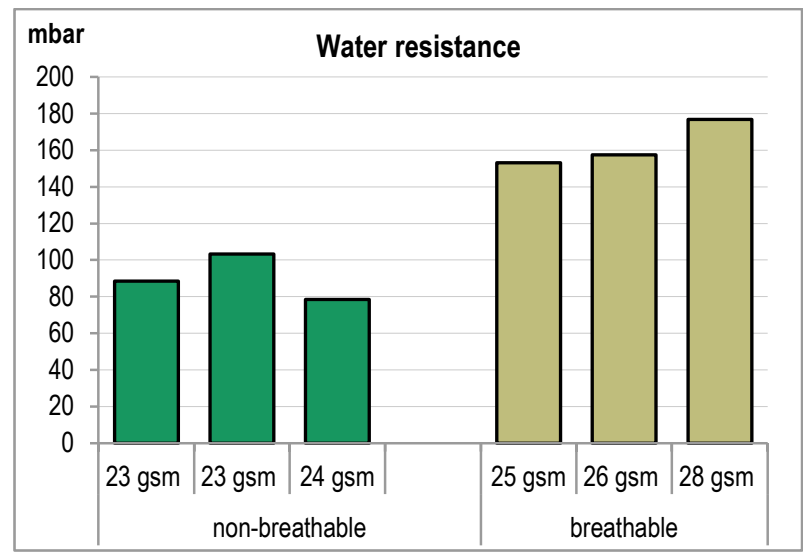

Figure 12 Water resistance

According to t-test results, breathability ( $p$ value is $0.02<0.05)$ has a significant effect on water resistance of back sheets. As for Pearson correlation, it is visible that there are very strong and positive relationships between breathability and water resistance, and between mass and water resistance. However, the relationship between breathability and water resistance is stronger than the relationship between the mass and water resistance.

\subsection{Bursting strength}

It is seen that bursting strength values of breathable samples are higher than that of non-breathable samples from Fig. 13. There is no clear tendency of increasing bursting strength with higher mass for non-breathable samples. On the contrary, it is clear that the bursting strength values of samples increase by increasing mass for breathable samples.

T-test results show that breathability ( $p$ value is $0.026<0.05$ ) has a significant effect on bursting strength of the back sheet. There are very strong and positive 
relationships between breathability and bursting strength, and between mass and bursting strength according to the Pearson correlation analysis. This means that bursting strength increases with breathability and increasing mass.

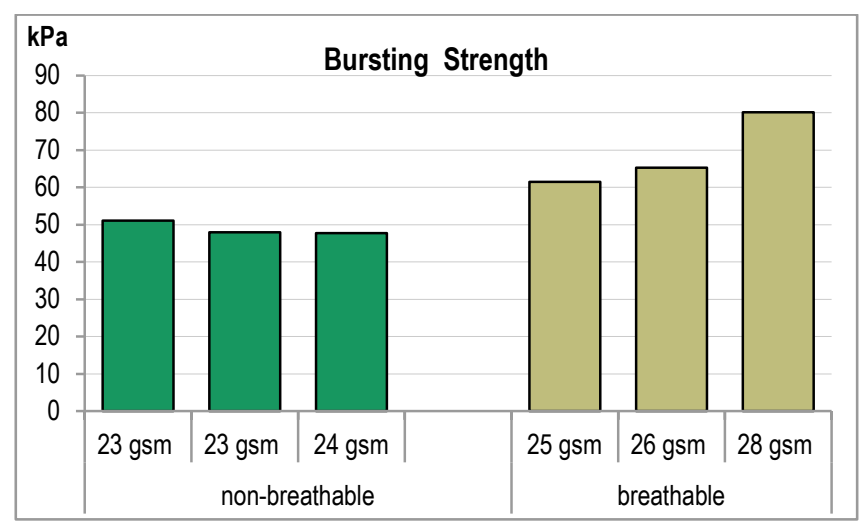

Figure 13 Bursting strength

Independent samples T-test and Pearson test results are shown in Tabs. 2 and 3, respectively. According to Tab. 2, group variances were assumed as equal for all variables since all significance values $>0.05$ in Levene's test. 2-tailed significance values displayed with * symbol were considered for the interpretation of t-test.

\begin{tabular}{|c|c|c|c|c|}
\hline & \multicolumn{2}{|c|}{$\begin{array}{l}\text { Levene's test for } \\
\text { equality of variances }\end{array}$} & \multicolumn{2}{|c|}{ T-test for equality of means } \\
\hline & $F$ & Sig. & $T$ & Sig. (2-tailed) \\
\hline \multirow{2}{*}{ Air permeability } & \multirow{2}{*}{1.791} & \multirow{2}{*}{0.252} & -0.045 & $0.966^{*}$ \\
\hline & & & -0.045 & $0.967 * *$ \\
\hline \multirow{2}{*}{$\begin{array}{l}\text { Water vapor } \\
\text { permeability }\end{array}$} & \multirow{2}{*}{6.384} & \multirow{2}{*}{0.065} & -5.167 & 0.007* \\
\hline & & & -5.167 & $0.035 * *$ \\
\hline \multirow{2}{*}{ Water resistance } & \multirow{2}{*}{0.025} & \multirow{2}{*}{0.881} & -7.094 & $0.002 *$ \\
\hline & & & -7.094 & $0.002 * *$ \\
\hline \multirow{2}{*}{ Bursting strength } & \multirow{2}{*}{7.515} & \multirow{2}{*}{0.052} & -3.454 & $0.026 *$ \\
\hline & & & -3.454 & $0.067 * *$ \\
\hline
\end{tabular}

*Equal variances assumed

** Equal variances not assumed

Table 3 Pearson correlation test results

\begin{tabular}{|l|c|c|c|}
\cline { 2 - 4 } \multicolumn{1}{c|}{} & Type & Mass & Thickness \\
\hline Air permeability & 0.023 & -0.195 & -0.025 \\
\hline Water vapor permeability & $\mathbf{0 . 9 3 3} * *$ & 0.612 & -0.161 \\
\hline Water resistance & $\mathbf{0 . 9 6 2} * *$ & $\mathbf{0 . 8 8 0}^{*}$ & 0.103 \\
\hline Bursting strength & $\mathbf{0 . 8 6 5}$ & $\mathbf{0 . 9 6 5} * *$ & 0.132 \\
\hline
\end{tabular}

*Correlation is significant at 0.05 level.

*** Correlation is significant at 0.01 level.

The definition of 'type' expresses breathability or nonbreathability for back sheet in Tab. 4 .

\section{CONCLUSIONS}

For breathable samples, while increasing mass, air permeability and water vapor permeability decrease, water resistance and bursting strength increase. On the other hand, the same tendency is not seen for non-breathable samples. Breathability is a water vapor transmission with diffusion of a material and it is important for healthy skin as determined above. Breathable samples have higher air permeability, water vapor permeability, water resistance and bursting strength than non-breathable samples.

T-test results display that breathability ( $p$ value is $0.07<0.05)$ has significant effect on water vapor permeability of back sheet. According to Pearson correlation, there is very strong and positive relationship between breathability and water vapor permeability. This means that breathability increases water vapor permeability in parallel.

\section{REFERENCES}

[1] Yaman, N., Senol, M. F., \& Tayyar, A. E. (2007). Alternative Test Methods for Assessing Mechanical Properties of Disposable Diapers. Fibres \& Textiles in Eastern Europe. 15(2) (61), 80-84.

[2] See http://edana.org

[3] Ozen, I., Cincik, E., \& Simsek, S. (2016). Thermal Comfort Properties of Simulated Multilayered Diaper Structures in Dry and Wet Conditions. Journal of Industrial Textiles. 46(1), 256-278. https://doi.org/10.1177/1528083715580521

[4] http://disposablediaper.net/files/dictionary.pdf

[5] http://www.plastik.it/en/product/breathable-textile-back sheet/

[6] https://www.linkedin.com/pulse/how-choose-correctbreathability-disposable-diaper-carlos pdf

[7] http://www.fatra.cz/en/products/breathable-films-andlaminates/breathable-films-sontek-f/

[8] Vakili, M. H., Ebadi-Dehaghani, H., \& Haghshenas-Fard, M. (2011). Crystallization and Thermal Conductivity of $\mathrm{CACO}_{3}$ Nanoparticle Filled Polypropylene. J Macromol Sci B, 50, 1637-1645. https://doi.org/10.1080/00222348.2010.543033

[9] Jakubowska, P. \& Sterzyñski, T. (2012). Thermal Diffusivity of Polyolefin Composites Highly Filled with Calcium Carbonate. Polimery, 57, 271-275. https://doi.org/10.14314/polimery.2012.271

[10] Yokura, H. \& Sukigara, S. (2010). Evaluation of the Wetness of Pantiliners. Textile Research Journal, 80, 1643-1647. https://doi.org/10.1177/0040517510365955

[11] Guo, Y., Ng, F. S. F., Hui, P. C. L. (2013). Heat and Mass Transfer of Adult Incontinence Briefs in Computational Simulations and Objective Measurements. International Journal of Heat and Mass Transfer, 64, 133-144. https://doi.org/10.1016/j.ijheatmasstransfer.2013.04.022

\section{Authors' contacts:}

Seval UYANIK, Dr.

Gaziantep University,

Technical Sciences High Vocational School,

Textile Department

Gaziantep/Turkey

+90 342 3601200/3644, uyanik@gantep.edu.tr

Hatice Kübra KAYNAK, Assoc. Prof.

Gaziantep University,

Textile Engineering Department

Gaziantep/Turkey

+903423172709, tuluce@gantep.edu.tr 